velocity indefinitely great) would seem to give the idea that the velocities are enormously great sometimes.

But it would appear that there are distinct physical conditions tending to limit the velocities of the molecules of a gas $(i . e$, the velocities capable of being acquired in the accidents of collision). First, there is the friction of the molecules in their passage through the enther. This must be considerable at high velocities, since meteoric dust is measureably retarded from this cause; and the relative friction or resistance to passage increases as the size of the body diminishes. So that probably by the known small size of molecules, the friction must be very great. Second, the resistance to passage is augmented from the fact that the molecule is in vibration (or some analogous motion about its centre of gravity) in the æther. The molecule is like a rough body then, stirring up the ather during its translatory motion, which must greatly ougment the resistance to passage. That there is friction in the ether by the passage of molecules is also confirmed, as it seems, by the fact that waves of heat and light contain energy. For how should a vibrating molecule impart energy to the ather without friction or resistance? The resistance is, in fact, a measure of the energy imparted. It appears a question whether, if the amplitude of the vibration (or motion which stirs up the æether) of molecules were known, the friction or resistance could not be calculated therefrom. For we know the number of vibrations accurately by the spectroscope, and the energy imparted to the ether (or contained in the waves), by the thermopile. To deduce the resistance to passage represented by the act of vibrating or swinging, we only appear to require the amplitude of vibration then. Perhaps a limiting value for this could be approximately arrived at.

Another cause tending to reduce the velocity of translatory motion possible to the molecules of gases in the accidents of collision, consists obviously in the fact that the internal motion of the molecule (vibration, rotation, \&c.) is proportional to the translatory velocity. So if a molecule attained an excessive translatory velocity, it would acquire an excessive vibration. This vibration would soon dissipate the energy in the æther in the form of waves of heat; and at the next succeding collisions, the molecule would acquire a relatively slower translatory motion, as it could not retain the necessary vibratory motion (internal motion) which is the essential accompaniment of a very high translatory velocity. So, therefore, from all these causes, the speeds capable of being acquired by the molecules of gases in the accidents of their encounters, are probably moderate; and far less, perhaps, than might be inferred from the theorem that the velocities vary between zero and a velocity indefinitely great.

Referring to a letter received from the late Prof. Clerk Maxwell, I find that-_"The number of molecules whose velocity is more than five times the mean velocity is an exceedingly small fraction of the whole number, less than one millionth. But if there were $10^{\text {roo }}$ molecules, many millions of these would have velocities greater than five times the mean, and yet this would produce no appreciable effect on the whole mass."

It seems, then, from the above that the number of molecules attaining high speeds is relatively rare. But it appears none the less worth noting distinctly that an indefinitely great velocity would mean a velocity indefinitely greater than the speed of light even. Suppose a few molecules to attain extreme stellar velocities of say 200 miles per second; it is evident that the friction in the æther (appreciable in the case of meteoric dust) would commence to tell in reducing the velocity. And as for a molecule supposed to acquire the speed of light itself, the molecule would (in traversing the æther) resemble much a cannon ball moving through the air at the normal speed of the air-molecules themselves-about 1600 feet per second-where the resistance to passage is very considerable, so it seems that there are in practice physical conditions limiting the velocities attainable by the molecules of gases; the resistance to passage augmenting more than in proportion to the velocity. It is not at all as if those molecules were moving in empty space. A molecule, if assumed to acquire an infinite velocity, would certainly have to be assumed to possess an infinite energy. It may be questioned whether even the total energy of translatory motion of the stars in the collective universe is infinite in sum; if not, then a single molecule with a supposed infinite velocity would require to have a greater total energy than this. The expression "infinite velocity" apparently only comes into the mathematical calculations applicable to a gas, supposed infinite in extent. But in these calculations it seems tacitly to be supposed that the molecules are moving in empty space, which is, however, not a fact. On the contraryt, the molecules move in a resisting substance whose obstruction to motion increases in a high ratio with the relocity of the bodies which traverse the resisting substance.

\section{DISCOVERY OF ANOTHER ANCTENT ARGILLITE QUARRY IN THE DELAWARE VALLIEY.}

BY H. O. MERCER, DOYLESTOWN, PA.

ON June 23, 1893, with the help of my assistant, Edward Frankenfield, I discovered another ancient argillite quarry, on the left bank of Neshaminy Creek, on the Warner farm, about three-quarters of a mile above the mouth of Mill or Labaska Creek (Bucks County, Pennsylvania).

No artificial hollows as at Gaddis Run have yet been found in the surrounding woods, but the rock here rising in a low cliff above the stream is argillite, and the water eating away the bank below it has revealed layers of chips, charcoal, large worked masses, pitted as if to split with the grain, pebble hammer stones and "turtle backs." A broken yellow jasper spear blade was found by Frankenfield 100 yards higher up the stream.

While the Gaddis Run quarry (noticed in Science of

tThe late Prof. Clerk Maxwell arrived at some data as to the size, etc, of molecules. If we assume a hydrogen molecule to vibrate through an amplitude (say) two-thirds of its diameter at a certain temperature, we can obviously get the total distance traversed through the ather in one second by the molecule through its vibrations, i. e., the total distance equal to the sum of the amplitudes of all the vibrations of the molecule in one second. That is, add together all the amplitudes, and find what distance that would make in a straight line. The size of the molecule is taken from Maxwell. I find this distance to be about ninety miles, i. e., the molecule vibrates at the rate of ninety miles per second, by the above assumed amplitude of vibration in terms of dimensions of molectle (which seems quite possible). According to Maxwell, two million hydrogen molecules placed in a row would occupy a millimetre. Hence it appears practicable that molecules can vibrate at a greater rate than a planetary velocity, which may see1: Surptising to some, considering how small the dimensions of molecules (and therefore their amplitudes of movement). The velocity of the earth in its orbit, for instance, is eighteen miles per second, as is known. The above comparatively high estimate for vibratory velocity of molecules (ninety miles per second, only a rough estimate, of course) may account rationally for the energy contained in the heat-waves of gases. and other bodies, which (enc $\rightarrow$ is a measure of the friction or resistance opposed by in iturit to the vibration or movement of a body in it. Calculations of this kind, although, of course, only approximate, may give us conceptions or ideas of the æether structure. If I had by me data as to the energy of the waves emitted. by a gas (radiating power), it would obviously not be difficult to compute the static resistance opposed by the ather to the vibratory movement or swing of the molecule in it, in terms of the weight of the molecule, i. e., in terms of gravity. Whether we have here a swing of the molecule, a movement of rotation oscillatory in its nature, or any movement of a repeated kind, the same considerations evidently in principle apply. In the above computation, the wave length of a hydrogen molecule is taken to average one thirty-nine thousandth of an inch. 
June 9, 1893,) is twenty-five miles by the river above Trenton, these much smaller and less noticeable workings lie only fourteen miles inland east northeast from the site of the celebrated gravel discoveries.

Neshaminy Creek flows into the Delaware (right bank) about three miles below Bristol, (Bucks Co., Pa.,) and a walk to the quarries by following up the winding stream from the river would cover a distance of about twenty miles.

\section{BOOK-RLVIEWS.}

Iowa Geological Survey, Volume I: First Annual Report, for 1892. By Samuel Calvin, State Geologist, Des Moines, 1893. 472 p., 8 vo. 10 plates and 26 figures.

IN addition to the administrative reports, the first report of the new survey contains seven papers, one of which is by the state geologist, three by the assistant state geologist C. R. Keyes, and the others by various members of the survey staff. The introductory paper, by Mr. Keyes, on the Geological Formations of Iowa is a summary of present knowledge of Iowa rocks. The author has here taken occasion to revise the classification of these formations to correspond with the progress made in their study in recent years with a very satisfactory result.

The Sioux quartzite is referred to as a doubtful element still in the geological section. The discovery of undoubted eruptive rock within these beds in southeastern Dakota by Culver and Hobbs, and in presumably the same beds in northwestern Iowa by the present survey, as set forth in fuller detail in Mr. S. W. Beyer's paper, is a matter of much interest and tend.s to add probability to the view entertained by Hayden that these rocks are much younger than commonly supposed.

The changes in nomenclature are much for the better, as for example, Oneata for Lower Magnesian; St. Croix for Potsdam; while in the Devonian the attempt to correlate the Iowa rocks with the New York section is abandoned. Prof. Calvin's work upon these formations has resulted in a four-fold division with names from places where the best sections are shown.

In the Lower Carboniferous, or Mississippian, the term Augusta is advocated for the terrane which Williams called the Osage, a name here shown to be inapplicable. We would differ with the author as to the advisability of dropping the term Warsaw as a sub-division of the Augusta in so far as concerns the rocks of Iowa, for though probably of limited development they present constant and easily recognized characters throughout the southeastern part of the state. An error occurs in the definition of the St. Louis limestone on page 72. The brecciated limestone is not the basal member, as asserted by the author, but in many sections along the Des Moines River there is shown to be from five to fifteen feet, or more, of a brown, quite regularly bedded magnesian limestome underneath the brecciated member and resting upon the arenaceous division of the Warsaw beds below.

In his discussion of the structure of the Coal Measures the author presents a valuable contribution to the literature of this subject, and advances conclusions acceptable alike for their simplicity and adherence to generally accepted principles of deposition.

The description of the Cretaceous formation is professedly taken from Professor Calvin's notes. Evidence is accumulating to show that these rocks have a much greater development in Iowa than heretofore considered. Three divisions are recognized and correlated with Hayden's Dakota, Fort Benton and Niobrara groups. The position of the Fort Dodge gypsum beds and the Nishuabotua sandstone are left undetermined.

In Mr. Beyer's paper there is given an account of the discovery in a deep well at Hull, Sioux County, Iowa, of quartz-porphyry - an eruptive rock, interstratified with sandstone. It occurred all the way from seven hundred and fifty-five feet down to twelve hundred and twenty feet, aggregating about one hundred and eighty-seven feet in thickness. To account for the presence of these rocks, the author advances two theories: (1) that they were due to secular outfiow of lava upon the ocean bottom in Palæozoic times, (2) that they represent intrusive subterranean sheets from a Post-Carboniferous volcano. The latter view is considered the most probable. In the absence of evidence as to the age of the sandstones, however, we see no reason why a third view may not be entertained, viz., that they were secular overflows from a Post-Carboniferous volcano.

In Mr. H. F. Bain's paper we have an interesting and instructive discussion of the St. Louis limestone as found in Mabaska County, Iowa, while Mr. G. L. Housen's paper deals with the economic phases of some Niagara limestones.

An Annotated Catalogue of Minerals and a Bibliography of Iowa Geology by $\mathrm{Mr}$. Keyes, complete the volume. The latter paper occupies more than half of the report and shows evidence of much care and painstaking labor, though a paper by the writer on the Keokuk limestone, published in the American Journal of Science for October, 1890, has evidently escaped the attention of the author.

The report has been printed from new and excellent type, the illustrations are exceptionally good, and altogether the volume in its make-up presents a pleasing contrast to many similar publications.

Typographical errors are not numerous, though some occur in prominent places, as, for examaple, in the word Survey on the title page, and in the words Tennessee and Territory on plate VI, though these can hardly be considered typographical. Errors appear also in the words Sandstore, p. 149, and Glacial, p. 139. A further criticism might be made on the lettering on the back of the volume, which scarcely seems in keeping with the pleasing effects of the text. But these are minor matters, and the survey and the state are to be congratulated upon the general excellence of their first report.

The Microscope: Its construction and management. Including Technique, Photo-micrography, and the Past and Future of the Microscope. By Dr. Henri Van Heurck, Professor of Botany and Director at the Antwerp Botanical Gardens; late President of the Belgian Microscopical Society; Hon. F. R. M. S. and New York M. S. English edition re-edited and augmented by the author from the fourth French edition, and translated by Wynne E. Baxter, F. R. M. S., F. G. S. With three plates and upwards of 250 illustrations. London, Crosby, Lockwood \& Son, New York, D. Van Nostrand Co., 1893. 382 p., Roy. 8vo.

I $\mathrm{T}$ is due mainly to Professor Abbe, of Jena, that, during the past twenty years, a real science of "microscopy" has come into existence, the aim of which is to develop the theory of the objective and to enlarge its hitherto limited powers. In fact the practical application which he has made of the laws of diffraction is the basis of by far the greater part of all the advance which has recently been made in the use of the microscope for scientific purposes. His investigations have not only resulted in the production of lenses of unequalled delicacy and perfection but have imparted a new interest to the study of purely theoretical optics and have given rise to a large and growing literature of the subject. The increased importance thus conferred on this phase of the matter, together with the rapid broadening of the field of research, has led to a desirable separation between the study of the microscope as an instrument, and the study of the results of its employment. 